\title{
1 Extensive transgressive gene expression in a homoploid hybrid species
}

2 Homa Papoli Yazdi ${ }^{*}$, Melissah Rowe ${ }^{2}$, Mark Ravinet ${ }^{3}$, Glenn-Peter Sætre ${ }^{4}$, Caroline Øien

3 Guldvog $^{4}$, Fabrice Eroukhmanoff ${ }^{4}$, Alfonso Marzal ${ }^{5}$, Sergio Magallanes ${ }^{5}$ \& Anna Runemark ${ }^{1}$

4

$5 \quad{ }^{1}$ Department of Biology, Lund University, SE-223 62 Lund, Sweden

$6 \quad{ }^{2}$ Department of Animal Ecology, Netherlands Institute of Ecology (NIOO-KNAW), 6700

$7 \quad \mathrm{AB}$, Wageningen, The Netherlands

$8{ }^{3}$ School of Life Sciences, University of Nottingham, Nottingham, UK

$9 \quad{ }^{4}$ Department of Biosciences, Centre for Ecological and Evolutionary Synthesis, University of

10 Oslo, PO Box 1066, N-0316, Oslo, Norway

$11{ }^{5}$ Departamento de Anatomía, Biología Celular y Zoología, Universidad de Extremadura, E-

12 506071, Badajoz, Spain

13

14 *Corresponding author: E-mail: Homa.Papoli_Yazdi@biol.lu.se

15

16

17

18

19

20

21

22

23 


\section{Abstract}

27 Hybridization is increasingly recognized as an important evolutionary force contributing

28 novel variation for selection to act on. While mis-expression in F1 hybrids is well

29 documented, how gene expression evolves in stabilized hybrid taxa and contributes novel

30 variation remains an open question, especially for hybrid species without an increase in

31 ploidy. As gene expression evolves in a stabilizing manner, break-up of co-evolved cis- and

32 trans-regulatory elements could lead to transgressive patterns of gene expression in hybrids.

33 Here, we address to what extent gonad gene expression has evolved in an old homoploid

34 hybrid, the Italian sparrow Passer italiae. Through comparing the gene expression of parental

35 species and F1 hybrids to that of the Italian sparrow, we find evidence for strongly

36 transgressive expression in the Italian sparrow, with $22 \%$ of the testis genes exhibiting

37 expression patterns outside the range of both parent species, compared to only $0.37 \%$ in the

38 F1s. In contrast, Italian sparrow ovary expression was similar to that of one parent species,

39 the house sparrow ( $P$. domesticus). Moreover, the Italian sparrow testis transcriptome is 26

40 times as diverged from those of the parent species as the parental transcriptomes are from

41 each other, despite being genetically intermediate. This highlights the potential for regulation

42 of gene expression to produce novel variation following hybridization. Genes involved in

43 mitochondrial respiratory chain complexes and protein synthesis are enriched in the subset

44 that is over-dominantly expressed in Italian sparrow testis, suggesting that selection on key

45 functions have molded the hybrid Italian sparrow transcriptome.

47 Keywords: Hybridization, gene expression, transgressive expression, testis, mito- 


\section{Introduction}

53 Hybridization is an important evolutionary process, contributing to novel genetic variation,

54 that natural selection can act on (Mallet 2005; Abbott, et al. 2013; Runemark, et al. 2019;

55 Taylor and Larson 2019). While divergence in parental genomes brings together novel allelic combinations in the hybrid, which may lead to a reduction in hybrid fitness (Dobzhansky

57 1936; Muller 1942), it is now clear that hybridization is frequent (Marques, et al. 2019;

58 Runemark, et al. 2019; Taylor and Larson 2019). Hence, we can no longer study

59 hybridization as an isolated phenomenon, and the processes at play in hybrids should be

60 integrated in our general understanding of how novel variation can arise. While there is

61 ample evidence for admixed hybrid genomes (Runemark, et al. 2019) and transgressive

62 hybrid phenotypes (Rieseberg, et al. 1999), the effect of hybridization on gene expression is

63 not well understood. Divergence in regulation of gene expression is thought to be the basis

64 for much of phenotypic evolution (Rest, et al. 2013; Hodgins-Davis, et al. 2015). In spite of

65 this, we lack an understanding of how gene expression contributes to novel phenotypes and

66 adaptation in old, stabilized hybrid taxa, in particular for homoploid hybrid species, with no

67 increase in ploidy level.

69 Gene expression evolves in a stabilizing manner where regulatory elements accumulate

70 compensatory mutations that keep gene expression at an optimum level for physiological

71 functions (Gilad, et al. 2006; Coolon, et al. 2014; Hodgins-Davis, et al. 2015). The compensatory evolution means that as hybridization breaks up co-inheritance of regulatory

73 elements, hybrids may experience novel combinations (Landry, et al. 2005; Renaut, et al.

74 2009), potentially leading to transgressive expression patterns, that transcends the range of 75 parental expression profiles. Indeed, transgressive gene expression has been reported in F1 
76 hybrids in several taxa, and the underlying regulatory divergence for transgressive expression

77 has been associated with divergence in cis- and trans-regulatory elements in the parental

78 species (Ranz, et al. 2004; Haerty and Singh 2006; Rockman and Kruglyak 2006; Malone and

79 Michalak 2008; Renaut, et al. 2009). In post-F1 generation hybrids, transcriptomes show a

80 higher level of transgressive expression due to uncoupling of regulatory elements in the

81 process of recombination. In the lake white fish Coregonus clupeaformis, the F2 hybrids

82 showed a higher level of nonadditive inheritance in gene expression compared to F1 hybrids

83 (Renaut, et al. 2009). An additional line of evidence of a non-linear relationship between

84 genetic composition and gene expression comes from recent studies on allopolyploid plant

85 taxa. Both preferential expression of one of the parental genomes (Edger, et al. 2017), and

86 tissue dependent expression of this dominance (Kryvokhyzha, et al. 2019) have been

87 documented in allopolyploids. Jointly, the transgressive expression in experimental hybrids and non-linear relationship between genomic composition and gene expression similarity, suggest that gene expression will not be proportional to the parental contributions to the

90 genome. Whether transgressive patterns of gene expression are found in old, stabilized

91 homoploid hybrid taxa is therefore important for understanding the potential of hybridization

92 to produce novel variation.

94 Gene expression studies in hybrids resulting from strongly divergent taxa has shown an 95 extensive level of transgressive expression arising from uncoupling of co-evolved cis- and 96 trans-regulatory elements in the hybrids (Haerty and Singh 2006; McManus, et al. 2010;

97 Coolon, et al. 2014). However, transgressive expression patterns in the hybrid of more

98 recently diverged species pairs can either arise due to polymorphic incompatible loci (Cutter

99 2012) or physiological response to hybrid dysfunction (Barreto, et al. 2015). In

100 interpopulation hybrids at F2 or later generation of copepod species, Tigriopus californicus, 
101

102

103

104

105

106

107

108

109

110

111

112

113

114

115

116

117

118

119

120

121

122

123

124

125

gene expression showed transgressive inheritance only in about $1.2 \%$ of the transcriptome and was linked to physiological response in hybrids (Barreto, et al. 2015). Additionally, recent study on F1 hybrids between the pied and collared flycatchers with few fixed differences and large number of shared polymorphisms showed a tissue-specific pattern of mis-expression. Testis had the highest divergence between the parental species but the lowest level of mis-expression in F1 hybrids (Mugal, et al. 2020). To which extent this pattern holds up across species, and how sorting of segregating polymorphisms may result in novel patterns of gene expression remains a challenge for researchers to address.

Here, we leverage a unique study system to address how gene expression evolves. We investigate gene expression in the homoploid hybrid Italian sparrow (Passer italiae) (Fig. 1), through combining data from the old, stabilized hybrid taxon, the parental species and experimental F1-hybrids. The Italian sparrow has arisen from hybridization between the house sparrow (P. domesticus) and Spanish sparrow (P. hispaniolensis) (Hermansen, et al. 2011; Hermansen, et al. 2014; Trier, et al. 2014; Elgvin, et al. 2017). The parent species diverged approximately 0.85 million years ago (Ravinet, et al. 2018) and the Italian sparrow originated within ca. 5800 years ago, most likely as the house sparrow expanded its range into Europe and hybridized with the Spanish sparrow (Ravinet, et al. 2018). This system provides a unique possibility to test to what extend an old, stabilized homoploid hybrid species has diverged in gene expression from the parent species, and how gene expression has evolved after hybridization. In this study, we compared the gene expression profiles of the gonads of the Italian sparrow to gene expression of the parental species and lab bred experimental F1 hybrids to address a) if Italian sparrows exhibit transgressive gene expression compared to the parent species and b) whether inheritance mode and misexpression in F1s predict which genes are transgressively expressed in Italian sparrows. 


\section{Results}

\section{Differential expression between the parental species}

129 Gene expression divergence in gonads between the parental species was strongly asymmetric

130 with testis showing a more conserved pattern of expression compared to ovary (Table 1). In 131 testis, 135 genes $(1.16 \%)$ and in ovary, 1382 genes $(11.65 \%)$ were significantly differentially expressed. Of the differentially expressed genes, $60.7 \%$ of genes in testis and $69.3 \%$ of genes in ovary were upregulated in the Spanish sparrow. A significantly higher proportion of genes that were differentially expressed in testis were located on the $Z$ chromosome ( 24 genes, hypergeometric test, $P$-value $<1.82-08)$. We found no evidence for functional enrichment among differentially expressed genes in parental species for neither testis nor ovary. Differential expression in Italian sparrows compared to the parental species

In contrast to its genome composition, intermediate of the parent species, the Italian sparrow testis gene expression differed more in comparison to the parental species than the parent species differed to each other (Table 1). About one-third of the testis transcriptome was differentially expressed compared to both parental species, whereas the ovary expression was similar to that of the house sparrow (Table 1, Figs. 2A-3A). In testis, 3536 genes $(30.45 \%)$ and 3581 genes $(30.9 \%)$ were differentially expressed in comparison to house and Spanish sparrow, respectively. In ovary, only 22 genes $(0.18 \%)$ differed from the house sparrow whereas 1508 genes $(12.63 \%)$ were differentially expressed compared to the Spanish

147 sparrow. Significant over-representation of Z-linked genes among the differentially expressed 148 genes was detected in testis but only in the comparison to Spanish sparrow (196 of the 3581 149 genes, hypergeometric test, $p$ value $=0.006$ ). Most genes in both testis and ovary were up150 regulated compared to house and down-regulated compared to Spanish sparrow (Chi-squared 
test $p$ value $=1.05 \mathrm{e}-06$ in testis and 0.001 in ovary) (Figs. 2B-3B).

153 Genes that were differentially expressed in Italian sparrow testis were enriched for similar

154 biological processes in comparison to both parent species. Primarily, functions involving

155 protein synthesis and mitochondrial gene expression and function were overrepresented. In

156 the comparison to house sparrow, 27 significant GO categories were found (Table S4), with

157 top biological processes involved in viral transcription, SRP-dependent co-translational

158 protein targeting to membrane, translation, ribosome and mitochondrial respiratory chain

159 complex I assembly. In comparison to the Spanish sparrow, the 15 enriched GO terms

160 reflected similar biological processes, with ribosome as the top GO term (Table S5). In ovary,

1616 GO terms were detected in the comparison to house sparrow with sodium ion

162 transmembrane transporter activity as the top term (Table S6) and 1 GO term, negative

163 regulation of protein phosphorylation detected in the comparison to Spanish sparrow (Table

164 S7).

165

Differential expression in F1 hybrids compared to the parental species

167 Both testis and ovary showed a more conserved pattern of expression between the F1 hybrid

168 and the house sparrow than between F1 hybrids and the Spanish sparrow (Table 1, Figs. 2A-

$1693 \mathrm{~A})$. The overall magnitude of differences to the parent species was much lower than for the

170 Italian sparrow. In testis, 106 genes $(0.9 \%)$ and 263 genes $(2.25 \%)$ were differentially

171 expressed compared to house and Spanish sparrows, respectively. In ovary, 30 genes $(0.25 \%)$

172 and 140 genes (1.15\%) showed a significant difference in expression compared to the house

173 and Spanish sparrows, respectively. Similar to the Italian sparrow, the pattern of up- and

174 down-regulation was consistent in both testis and ovary in the comparison to each of the

175 parental species (Figs. 2B-3B). A larger number of genes were up-regulated in F1 hybrid in 
176 the comparison to house sparrow and down-regulated in the comparison to Spanish sparrow

177 (Chi-squared test $P$-value $=1.96-05$ in testis and 0.01 in ovary). As in the Italian sparrow,

178 there was an over-representation of Z-linked genes among those differentially expressed

179 between F1 hybrids and Spanish sparrows ( 31 of the 263 differentially expressed genes,

180 hypergeometric test, $P$-value $=2.42-06)$. The enriched functions were different to those

181 enriched for Italian sparrows. Testis genes differentially expressed in F1 showed functional

182 enrichment for primarily collagen catabolic process. In the comparison to house sparrow, 46

183 GO terms were significantly over-represented. Among these GO terms, $20 \mathrm{GO}$ terms had an

184 Padj $<0.01$, whereas there were few significant GO terms compared to Spanish sparrows

185 with top GO term common with the comparison to house sparrow (Tables S8 and S9). The

186 top 5 GO terms were enriched in proteinaceous extracellular matrix, extracellular matrix

187 structural constituent, extracellular vesicle, collagen trimer and collagen catabolic process. In

188 ovary, while there was no functionally significant term associated with differentially

189 expressed genes in F1 compared to the house sparrow, there were 28 significant GO terms in

190 the comparison to Spanish sparrow with the top category to be response to vitamin D (Table

$191 \mathrm{~S} 10)$.

192

\section{Classification of inheritance patterns of gene expression}

194 Gene expression was generally conserved in both Italian sparrow and F1 hybrid (Table 2),

195 but in the testis of Italian sparrow, 2611 genes (22.71\%) showed a non-conserved pattern of

196 inheritance with transgressive expression and house-dominant being the two largest

197 categories (Fig. 4C). Transgressively expressed genes in Italian sparrow comprised 22\% of

198 the testis transcriptome tested for inheritance. In contrast, in F1 testis only $0.37 \%$ of the genes

199 were transgressively expressed (Fig. 4D). The majority of the genes with non-conserved

200 pattern of inheritance in Italian sparrow ovary, over $96 \%$ of the genes, had a house-dominant 
pattern of expression (Fig. 4E). In contrast to the high incidence of transgressive expression observed in Italian sparrow testis, only 3 genes $(0.028 \%)$ were transgressively expressed in ovaries. Gene expression in F1 ovary was more conserved compared to that of the Italian sparrow. Out of 376 genes with non-conserved pattern of inheritance, the two largest categories of inheritance were additive and house-dominant inheritance pattern (Fig. 4F).

Overdominant genes in Italian sparrow testis were enriched for functional categories involved in protein synthesis, mitochondrial protein complex and gene expression and binding of sperm to zona pellucida (Table S11). We found a gene network with significant proteinprotein interaction (PPI Enrichment: 1.0E-16) among the overdominant genes in Italian sparrow (Fig. 5, Fig. S4). A different set of genes were underdominant in Italian sparrow, with functions including regulation of cellular component size and negative regulation of neuron projection development. Overdominant genes in F1 testis were functionally enriched

214 for different GO-terms, including collagen catabolic process and proteinaceous extracellular matrix (Table S12). The only significant GO term for underdominant genes in F1 testis was voltage-gated potassium channel complex.

\section{Comparison of gene expression divergence in respect to parent species between Italian}

220 To evaluate how gene expression evolves over time asking whether mis-expression in early generation hybrids predicts differential expression in Italian sparrows, we checked if the species in F1 hybrids also were differentially expressed in the Italian sparrow (Figs. 2C-3C).

224 In testis, $1.28 \%$ of the genes that were differentially expressed in Italian sparrows compared to house sparrow were also differentially expressed in experimental F1 hybrids, whereas in 
comparison to Spanish sparrows it was $3.9 \%$. In ovary, only 1 gene $(2 \%)$ was differentially

227 expressed in F1 and Italian sparrow compared to house sparrow, whereas 5.9\% were

228 differentially expressed in F1 hybrids and Italian sparrows in comparison to Spanish

229 sparrows. The majority of the commonly differentially expressed genes were differentially

230 expressed in the same direction (i.e., up- or down-regulated) in both testis and ovary, both in

231 F1 hybrids and Italian sparrows. Testis genes commonly differentially expressed in F1 hybrid

232 and Italian sparrow compared to house sparrow were enriched in extracellular vesicle, insulin

233 like growth factor binding, extracellular matrix structural constituent and extracellular matrix

234 component. In the comparison to Spanish sparrow testis, only one significant GO term,

235 cAMP binding was detected.

237 Mode of regulatory divergence and prediction of transgressive expression in Italian

238 sparrows

239 To address if the regulatory basis can predict transgressive gene expression in hybrid species,

240 we classified genes dependent on their regulatory basis (Table 3). We expect genes under cis-

241 trans compensatory regulation and trans-regulated genes to more easily produce transgressive

242 patterns of gene expression in later generation hybrids than cis-regulated genes, as

243 recombination may de-couple cis- and trans- or different trans-elements in the sorting of

244 parental variation in the hybrid lineage. Therefore, we checked the percentage of genes

245 transgressively expressed in the Italian sparrow depending on the mode of regulatory

246 divergence. We found that $16 / 130$ genes $(12 \%)$ of the trans-regulated testis genes were

247 transgressively expressed in Italian sparrow, and 28/159 genes (18\%) of the genes under cis-

248 trans compensatory regulation were transgressively expressed in Italian sparrows. Finally, we

249 tested whether genes with a non-additive inheritance, that were transgressively expressed in

250 F1 hybrids, were more likely to be transgressively expressed in the Italian sparrow. We found 

were transgressively expressed in Italian sparrow testis.

253

\section{Discussion}

255 In this study, we aimed to document the evolution of gene expression in the gonads of a 256 homoploid hybrid species, the Italian sparrow. An extensive level of transgressive expression

257 was found in Italian sparrow testis, with an over-expression of genes involved in functions

258 related to mitochondrial respiratory chain and, cytosolic and mitochondrial ribosomal

259 proteins, as well as proteins involved in protein folding and the proteasome complex. In

260 contrast to testis, the gene expression pattern in the ovary was asymmetric compared to

261 parental species, with a house-dominant expression in the Italian sparrow. Experimental F1

262 hybrids showed a much more conserved pattern of gene expression in both testis and ovary.

263 In the following sections, we discuss the potential implications of our results and consider the

264 limitations of these data.

\section{Extensive transgressive expression in Italian sparrow testis}

267 About $22 \%$ of testis transcriptome in Italian sparrow showed transgressive expression pattern,

268 while this level was less than $1 \%$ in the F1 hybrid. Transgressive gene expression, despite the

269 fact that gene expression is conserved between parent species, is expected to occur in later

270 generation hybrids due to the uncoupling of co-evolved cis- and trans-regulatory elements

271 through recombination (Rieseberg, et al. 2003; Mallet 2007). There are, however, few studies

272 of gene expression in post F1-hybrids. In Lake whitefish, F2 hybrids showed higher

273 misexpression and percentage of genes with nonadditive inheritance compared to F1 hybrids

274 (Renaut, et al. 2009). Transgressive expression is commonly referred to "mis-expression" in

275 early generation hybrids while Italian sparrow is a successful hybrid taxon likely formed 
276 within the last 5.800 years (Ravinet, et al. 2018). Here, we show that transgressive

277 expression is found not only as mis-expression in early generation hybrids but remains in

278 well-functioning homoploid hybrid taxa long after hybridization. Hence, evolution of the

279 regulation of gene expression following hybridization may produce novel expression

280 phenotypes from intermediate genomes. In hybrid lineages, transgressive segregation, which

281 leads to extreme phenotypes, has been considered as a major mechanism by which extreme or

282 novel adaptations observed in new hybrid ecotypes or species arise (Rieseberg, et al. 1999),

283 but sorting of regulatory elements have not formally been suggested to contribute to this. This

284 research suggests that break-up of co-evolved regulatory elements, resulting in transgressive

285 patterns of gene expression, partly can explain the generation of transgressive phenotypes in

286 hybrid taxa.

287

\section{Transgressive expression arising in spite of low parental divergence}

289 Hybrid incompatibilities arisen due to bringing together novel genetic combinations have

290 been mainly considered when the parental species are fixed for alleles potentially contributing to reproductive isolation (Cutter 2012). In recently diverged species, reproductive incompatibility may arise due to polymorphic loci within each lineage before

293 fixation for the incompatibility alleles (Cutter 2012). Therefore, if transgressive expression in

294 the Italian sparrow is driven by bringing together cis- and trans-regulatory variants not yet co-adapted, this must either be by bringing together polymorphic loci in each of the parental species or novel mutations that have occurred in Italian sparrow since isolation from the parental species. Each of these hypotheses can be evaluated in future work by studying the F1 and F2 hybrids and the direct parents of the cross in order to find cis and trans-regulatory variations. Interestingly, during ca. 5.800 years of evolution, Italian sparrows have achieved a 
million years, in spite of them being genomically intermediate (Elgvin, et al. 2017)

\section{Tissue- and parent specific patterns of differentiation in gene expression}

304 We find that the degree of difference in gene expression is tissue- and parent specific. We generally observed fewer differentially expressed genes relative to house sparrow than relative to the Spanish sparrow, both for Italian sparrows and F1 hybrids, and especially for expression, and even result in misexpression (Runemark, Eroukhmanoff, et al. 2018). An additional explanation for a more conserved expression pattern in ovary could be a contribution of the $\mathrm{W}$ chromosome. While we can assume that F1 hybrids examined in this affects gene expression is an interesting future line of inquiry. Finally, we cannot exclude that a technical artefact contributes to the house-dominant pattern of expression. More specifically, only 3 Spanish sparrows were used in the analysis of ovary transcriptome, this

317 finding may be driven by large within-species variance in ovarian gene expression.

\section{Enrichment of over-dominant genes in Italian sparrow for translation and}

321 A large set of genes involved in protein synthesis were over-expressed in Italian sparrow testis compared to both parents. These include a set of ribonucleoproteins present in both required for maximal rate of protein synthesis and SRP (signal recognition particle), a ribonucleoprotein that recognizes and targets specific proteins to the endoplasmic reticulum 
in eukaryotes. RNA binding proteins play an important role in post-translational regulation of

327 gene expression and spermatogenesis and appear to be key regulatory factors that ensure

328 male fertility (Paronetto and Sette 2010; Phillips, et al. 2019). Several genes coding for

329 subunits of T-complex protein Ring Complex (TRiC) (CCT4, CCT5, CCT6A, TCP1) were

330 also among the overdominant genes. The TRiC complex aids in the folding of about $10 \%$ of

331 the proteome. Subunits of TRiC complex has shown to be required for spermatogenesis

332 (Counts, et al. 2017) and have shown evidence for positive selection among the seminal fluid

333 genes between house and Spanish sparrows (Rowe, et al. 2020). Another category of gene

334 networks which were upregulated in Italian sparrow included genes encoding for components

335 of all mitochondrial respiratory chain enzymatic complexes. Additionally, genes encoding for

336 chaperone proteins involved in the assembly of these enzymatic complexes such as

337 TIMMDC1 were also over-expressed.

339 In Italian sparrow testis, mito-nuclear genes have been shown to be important in generating

340 reproductive isolation in the Italian sparrow (Trier, et al. 2014), and mito-nuclear sites have

341 been under selection for inheritance of the house sparrow allele in Italian sparrows

342 (Runemark, Trier, et al. 2018). Although the mitochondrion has its own genome, more than

$34398 \%$ of its proteins are encoded in the nuclear genes and its correct function requires a

344 coordinated expression of both nuclear and mitochondrial genomes (Ryan and Hoogenraad

345 2007). Therefore, the upregulation of genes involved in respiratory chains and protein

346 synthesis corroborate the evidence for a strong effect of hybridization on genes associated

347 with metabolism in other bird taxa (Wagner, et al. 2020). Overexpression of cytosolic

348 ribonucleoproteins and mitochondrial respiratory chain enzymes has also been observed in

349 later generation hybrids (F3+) in copepod species Tigriopus californicus and has been linked

350 to cellular responses to physiological dysfunction (Barreto, et al. 2015). Our study thus 
contributes to the growing body of evidence of mito-nuclear interactions as important reproductive barriers (Hill 2017), and provides a unique insight into altered patterns of gene expression as a possible resolution to the conflict.

\section{Conclusion}

This study presents the first evidence for transgressive gene expression in a wild homoploid hybrid species. The strongly divergent gene expression profile in Italian sparrow testis highlights the potential of intermediate hybrid genomes to rapidly evolve through altered regulation of gene expression. Comparing patterns of gene expression in wild homoploid hybrid species to those seen in experimental F1 hybrids, we document rapid evolution of gene expression, especially for networks of genes involved in mitochondrial respiratory chain enzymes and protein synthesis. The strongly divergent testis transcriptome was unexpected given the low parental divergence, highlighting that alleles contributing to reproductive isolation may be polymorphic rather than fixed. In contrast, Italian sparrow ovary had a transcriptome similar to that of the house sparrow. Future studies should therefore evaluate the current results in more tissues. Using pedigrees of parents and hybrid individuals would also improve the power to identify the regulatory underpinnings of gene expression. Finally, examining the link between transgressive gene expression and transgressive hybrid phenotypes is likely to significantly increase our understanding of how novel variation arise

370 from hybridization.

Materials and methods

\section{Sampling, RNA extraction, library preparation, and sequencing}

375 We compared the gene expression of Italian sparrows to its two parent species, house and 376 Spanish sparrow and their experimental F1-hybrids. As the species differ slightly in 
377 phenology, birds were sampled during their peak reproductive periods at their respective

378 locations. Spanish sparrows and F1 hybrids were sampled near Olivenza, Spain $\left(38^{\circ} 40^{\prime}\right.$

$\left.37956^{\prime \prime} \mathrm{N}, 7^{\circ} 11^{\prime} 17^{\prime \prime} \mathrm{W}\right)$ in March 2016 and 2017, house sparrows in Oslo, Norway (59 55' 2"N,

$380 \quad 10^{\circ} 46^{\prime} 11^{\prime \prime E}$ ) in May 2016 and Italian sparrows from Montanari in the Gargano peninsula

$381 \quad\left(41^{\circ} 54^{\prime} 36.8^{\prime \prime} \mathrm{N}, 1^{\circ} 51^{\prime} 13.0^{\prime \prime} \mathrm{E}\right)$ in May 2017 (Fig 1). Experimental F1 hybrids were bred in

382 outdoor cages using house sparrow females and Spanish sparrow males. All other birds were

383 trapped using mist nets outside or within cages. Birds were immediately euthanized by

384 cervical dislocation, and gonads (ovary and left testis) were harvested directly after death.

385 Sampling was performed between 10:00 and 16:00, with individuals from each of the species

386 being sampled over most of the day, in order to avoid biases in sampling time. The gonads

387 were stored in RNAlater, and immediately stored at -80 degrees, with extractions later

388 performed at the University of Oslo using the Qiagen miRNeasy micro kit. Samples were

389 prepped with TruSeq ${ }^{\circledR}$ Stranded mRNA library prep from Illumina on an automated Perkin

390 Elmer Sciclone NGSx liquid handler and sequenced in the Norwegian Sequencing Center in

391 Oslo, as paired-end (2x150 bp) on the Illumina Hiseq4000. The number of reads obtained per

392

each sample is reported in Table S1. As F1 hybrids were bred in an area where house and

393

Spanish sparrows are sympatric (Olivenza, Spain; see Fig 1) and correct identification of

394 females can be challenging, we performed a post-hoc genomic analysis based on

395 mitochondrial and genomic DNA to ensure that only individuals that clustered with the

396 expected species were included in the analyses (Supplementary materials and methods, Figs.

397 S1-S2).

\section{Read mapping, quality check and counting}

400 We mapped reads from samples of all four groups (testis sample size: house sparrow $=5$,

401 Spanish sparrow $=5, \mathrm{~F} 1$ hybrid $=5$, Italian sparrow $=5$; ovary sample size: house sparrow $=$ 
5 , Spanish sparrow $=3, F 1$ hybrid $=8$ and Italian sparrow $=5$ ) to the house sparrow reference genome using STAR2 v2.7.2b (Dobin, et al. 2013) with default parameters and the house sparrow gene annotation as reported in (Elgvin, et al. 2017). Over 90\% of the reads mapped successfully (Table S1). The house sparrow general feature format (GFF) file contained 14,734 annotated genes of which $92.52 \%$ were anchored to chromosomes and $7.48 \%$ were located on unanchored scaffolds. Of the genes anchored to chromosomes, 12,595 genes were

homogeneity in quality across our samples, we used RSeQC (Wang, et al. 2012) to measure

410 RNA integrity at the transcriptome level for each sample by calculating Transcript Integrity

411 Number (TIN). The median TIN scores across samples ranged between 73.7 and 85.9 (Table

412 S3). We counted the number of reads mapping to the house sparrow gene features using

413 HTSeq v0.9.1 (Anders, et al. 2015). Read counting was performed for all reads with

414 minimum quality score of 30 and it was configured to handle reverse-stranded sequencing

415 data, with the parameter controlling for overlapping gene features set to union. We created a

416 dendrogram to show sample relationships. The main split was clearly between tissue types,

417 i.e. testis and ovary (Figure S3).

\section{Differential gene expression analysis}

420 We analyzed the raw read counts obtained from htseq-count using the R package DESeq2

421 (Anders and Huber 2010; Love, et al. 2014). We first tested genes for differential expression

422 between house and Spanish samples. We then compared each of the parents to the

423 experimental F1 hybrid and the Italian sparrow. We pre-filtered the data to a minimum of

424 total read counts of 10 across at least half of the samples in each pairwise comparison. To

425 generate more accurate estimates of $\log 2$ fold change (LFC) for genes with low count number

426 or large dispersion, we shrank LFC estimates. We considered genes to be differentially 
expressed if they showed False Discovery Rate (FDR) Padj $<0.05$ and shrunken LFC $>0.32$.

428

\section{Classification of gene expression inheritance in experimental F1 hybrids and Italian}

\section{sparrows}

431 The mode of inheritance for differentially expressed genes was determined following

432 (McManus, et al. 2010). We normalized gene expression using median of ratios method in

433 DESeq2 (Love, et al. 2014). Genes whose total expression in hybrids deviated significantly

434 more than 1.25-fold ( $\mathrm{LFC}>0.32)$ from that of either parent were considered to have non-

435 conserved inheritance. These genes were classified as having additive, dominant, under-

436 dominant, or over-dominant inheritance, based on the magnitude of the difference between

437 total expression in the Italian sparrow / experimental F1 hybrid and in each parental species.

438 Genes for which expression in the Italian sparrow / experimental F1 hybrid was less than for

439 house sparrows and greater than for Spanish sparrow (or vice versa) were classified as

440 additive; genes for which expression in Italian sparrow / experimental F1 hybrid was similar

441 to one of the parents were classified as dominant; and genes for which expression in Italian

442 sparrow / experimental F1 hybrid was either greater than or less than both parent species

443 were classified as over-dominant and under-dominant, respectively (Figs. 4A-4B).

\section{Allele-specific expression and cis- and trans- regulatory divergence assignment}

446 Conserved expression level between parents controlled by compensatory variation in parental

447 species is often associated with misregulation in their hybrids (Denver, et al. 2005; Landry, et

448 al. 2005; Goncalves, et al. 2012).-By using sites in experimental $F_{1}$ hybrids that contain both

449 parental alleles, we measured allele specific expression, and compared that to expression

450 levels in the parental species to infer whether the divergence is due to cis-, trans- or

451 compensatory evolution. A typical approach for the study of ASE is to select the sites for 
which the parental species are fixed for two different alleles and study the ASE in

453 heterozygote hybrids (Wittkopp, et al. 2004). House and Spanish sparrows diverged only

454 about 0.85 MYA, with many polymorphisms still shared between the two species. We

455 therefore took an approach similar to the one used in other studies with species pairs

456 containing high number of shared polymorphisms and few fixed differences (Mugal, et al.

457 2020).

458

459 We performed the SNP calling and filtering as described in the section "Genetic

460 Characterization of Samples" (Supplementary Materials and Methods). We additionally

461 filtered the sites for DP of minimum 10, base quality of 20 and mapping quality of 60 . We 462 used the R package MBASED (Mayba, et al. 2014) in the unphased mode to identify genes 463 with allele-specific expression. We filtered the MBASED results for the FDR $<0.05$ and 464 major allele frequency of minimum 0.7 . To balance the power, we chose 5 individuals for 465 each house, Spanish, F1 and Italian sparrow in testis and 3 individuals of each group for 466 ovary. To identify allele-specific expression at the population level, we required genes to 467 show significant allele-specific expression in at least two individuals. Following (McGirr and 468 Martin 2019), we divided the regulatory categories as follow: Cis-regulatory divergence was attributed to genes that are differentially expressed between parents and show allele-specific

470 expression in hybrids. Trans-regulatory divergence was assigned to genes that are

471 differentially expressed between parents and do not show allele-specific expression in

472 hybrids. Putative compensatory regulatory variation was determined if a gene 1) did not show

473 differential expression between parents, 2) showed significant allele-specific expression in

474 hybrids, and 3) did not show allele-specific expression in parents.

477 Gene ontology (GO) analysis was done for differentially expressed genes in each pairwise 
comparison. GO functional annotations and gene descriptions were obtained for protein

479 sequences from the entire house sparrow protein set as described in (Rowe, et al. 2020) using

480 PANNZER (Koskinen, et al. 2015). Functional enrichment of GO terms present in the set of

481 differentially expressed genes relative to the background consisting of all genes expressed

482 and tested for differential expression was performed using the clusterProfiler (Yu, et al. 2012)

483 and significant enrichment was determined at FDR $<0.05$. Interactions among proteins with

484 significant GO terms were predicted using STRING-v11 (Szklarczyk, et al. 2019) using

485 "Experiment", "Databases" and "Co-expression" as interaction sources. We set the minimum

486 required interaction score to the highest confidence (0.9) and used only the query proteins to

487 build the interaction network after removing the disconnected nodes in the network. The

488 obtained network was then exported to Cytoscape (Shannon, et al. 2003) and major

489 representations of biological processes were detected using ClueGO (Bindea, et al. 2009)

$490 \quad$ with $\operatorname{Padj}<0.01$.

$492 \quad$ Animal Ethics

493 In Spain, all trapping and sampling of birds was conducted in accordance with Spanish

494 Animal Protection Regulation RD53/2013, and all methods were approved by the

495 Institutional Commission of Bioethics at the University of Extremadura (CBUE 49/2011).

496 Birds were sampled in Oslo with permission from Miljø-direktoratet (2016/2225). In Italy, all

497 birds were sampled with permission from ISPRA (protocol number 12404) and with

498 permission (no. 305) from regione Puglia. All samples taken from Italy to Oslo in accordance

499 with the Nagoya protocols.

500

501 Scripts for the analyses

502 All scripts written for the analyses presented in this manuscript are deposited under 


\section{Author contributions}

506 A.R. and H.P.Y. conceived of the study. A.M. raised the hybrids and M. Ro., M. Ra., A.R.,

507 F.E, C.O. and G-P. S. performed field work and sampling, C.O. performed the molecular lab work, and H.P.Y. designed and performed the bioinformatical analysis based on discussions A.R., M.Ra and M.Ro.

\section{Acknowledgements}

513 We thank Angelica Cuevas for assistance with sampling. The computations were enabled by

514 resources in project SNIC2020-6-222 provided by the Swedish National Infrastructure for

515 Computing (SNIC) at UPPMAX, partially funded by the Swedish Research Council through 516 grant agreement no. 2018-05973. This work was financed by a Norwegian Research council grant to G-P. S. and A. R. and a Wenner-Gren and a Swedish Research Council grant to A.R. 
530 Fig. 1. Species distribution and study design. (A) Top: Illustrations of male plumage patterns

531 in house, Italian, and Spanish sparrows modified from (Svensson, et al. 1999). Bottom: A

532 distribution map of house, Italian, and Spanish sparrows throughout Europe and northern

533 Africa (Summers-Smith). This picture is modified from (Elgvin, et al. 2017). (B) Pedigree of

534 the F1 hybrids with house sparrow mother and Spanish sparrow fathers.

535

536 Fig. 2. Gene expression in Italian sparrow and experimental F1 hybrid in comparison with 537 parental species for testis. A) Log2 fold change (LFC) as a function of mean of normalized counts. B) Proportion of up- and down-regulated genes. Dark color: up-regulated, light color:

539 down-regulated. C) Venn diagram depicting the intersection between differentially expressed

540 genes between the experimental F1 hybrid and Italian sparrow with each of the parental

541 species. F1h: experimental F1 hybrid - house sparrow; Ih: Italian sparrow - house sparrow;

542 F1S: experimental F1 hybrid - Spanish sparrow; IS: Italian sparrow - Spanish sparrow.

543 Purple: F1 hybrids, Orange: Italian sparrows.

544

545 Fig. 3. Gene expression in Italian sparrow and experimental F1 hybrids in comparison with

546 parental species for ovary. A) Log2 fold change (LFC) as a function of mean of normalized

547 counts. B) Proportion of up- and down-regulated genes. Dark color: up-regulated, light color:

548 down-regulated. C) Venn diagram depicting the intersection between differentially expressed

549 genes between the experimental F1 hybrid and Italian sparrow with each of the parental

550 species. F1h: experimental F1 hybrid - house sparrow; Ih: Italian sparrow - house sparrow;

551 F1S: experimental F1 hybrid - Spanish sparrow; IS: Italian sparrow - Spanish sparrow.

552 Purple: F1 hybrids Orange: Italian sparrows. 
553 Fig. 4. Inheritance pattern of gene expression in testis and ovary in Italian sparrows and

554 experimental F1 hybrids. A and B: Schematic figures representing the classification of

555 inheritance patterns. C and D: Scatter plots showing shrunken log2 fold change (LFC) in

556 testis between the Italian sparrow and experimental F1 hybrid with the house sparrow on the

$557 x$-axis and with Spanish sparrow on the $y$-axis, respectively. E and F: Scatter plots show

558 shrunken $\log 2$ fold change (LFC) in ovary between the Italian sparrow and experimental F1

559 hybrid with the house sparrow on the $x$-axis and with Spanish sparrow on the $y$-axis,

560 respectively. Grey points in each graph depicts the total number of genes studied for gene

561 expression with those colored representing the ones significantly different from parental

562 species to be divided into each of the inheritance categories (Conserved: grey, additive: pink,

563 house dominant: blue, Spain dominant: red, transgressive (over-dominant and under-

564 dominant: yellow). Grey dotted lines indicate the fold-change threshold of 1.25 used for

565 classification of inheritance pattern. Regression line represents the major variation in $\log 2$

566 fold change. F1h: experimental F1 hybrid - house sparrow; Ih: Italian sparrow - house

567 sparrow; F1S: experimental F1 hybrid - Spanish sparrow; IS: Italian sparrow - Spanish

568 sparrow.

569

570 Fig. 5. Gene ontology network represented in overdominant genes in testis of Italian sparrow.

571 Different colors depicts different significant biological processes. Circle size represents

572 adjusted $P$-value for each node with all Padj $<0.01$.

573

574

575

576 
578 Table 1. Number of differentially expressed genes and $\log 2$ fold change (LFC) with Padj<

$579 \quad 0.05$ and $\mathrm{LFC}^{*}>0.32$

\begin{tabular}{cllllll}
\hline & Testis & \multicolumn{5}{c}{ Ovary } \\
\hline Comparison & Significant & LFC $>$ 0 & LFC $<$ 0 & Significant & LFC > 0 & LFC < 0 \\
\hline Spain - House & 135 & 82 & 53 & 1382 & 958 & 424 \\
F - House & 106 & 77 & 29 & 30 & 16 & 14 \\
F - Spain & 263 & 125 & 138 & 140 & 39 & 101 \\
Italy - House & 3536 & 1962 & 1574 & 22 & 13 & 9 \\
Italy - Spain & 3581 & 1779 & 1802 & 1508 & 394 & 1114 \\
\hline * LFC: Log Fold Change & & & & &
\end{tabular}

* LFC: Log Fold Change

581 Table 2. Number and percentage of genes in each inheritance category.

\begin{tabular}{cllll}
\hline \multicolumn{2}{c}{ Testis } & \multicolumn{3}{l}{ Ovary } \\
\hline Inheritance & $\mathbf{F}_{1}$ & Italy & $\mathbf{F}_{1}$ & Italy \\
\hline Conserved & $11515(99.14 \%)$ & $8883(77.30 \%)$ & $11600(96.9 \%)$ & $10889(92.26 \%)$ \\
Additive & $6(0.05 \%)$ & $2(0.02 \%)$ & $272(2.27 \%)$ & $19(0.16 \%)$ \\
house dominant & $45(0.39 \%)$ & $54(0.47 \%)$ & $94(0.78 \%)$ & $895(7.58 \%)$ \\
Spain dominant & $4(0.03 \%)$ & $25(0.22 \%)$ & $6(0.05 \%)$ & $7(0.06 \%)$ \\
Underdominant & $12(0.1 \%)$ & $1205(10.47 \%)$ & $2(0.17 \%)$ & $3(0.02 \%)$ \\
Overdominant & $33(0.27 \%)$ & $1325(11.53 \%)$ & $2(0.17 \%)$ & $1(0.008 \%)$ \\
\hline
\end{tabular}

582

583

584

585

586

587 
588 Table 3. Counts of genes with ASE and cis-, trans- and CE*-evolution

\begin{tabular}{cccccccccc}
\hline & \multicolumn{1}{c}{ Testis } & \multicolumn{7}{c}{ Ovary } \\
\hline Comparison & ASE & cis & trans & CE & ASE & cis & trans & CE \\
& & & & & & & & \\
\hline House & 261 & - & - & - & 72 & - & - & - \\
Spain & 456 & - & - & - & 118 & - & - & - \\
\hline F1 & 164 & 5 & 130 & 159 & 54 & 9 & 1373 & 45
\end{tabular}


Abbott R, Albach D, Ansell S, Arntzen JW, Baird SJ, Bierne N, Boughman J, Brelsford A, Buerkle CA, Buggs R, et al. 2013. Hybridization and speciation. J Evol Biol 26:229-246. Anders S, Huber W. 2010. Differential expression analysis for sequence count data. Genome Biology 11.

613 Anders S, Pyl PT, Huber W. 2015. HTSeq-a Python framework to work with high-throughput sequencing data. Bioinformatics 31:166-169.

615 Barreto FS, Pereira RJ, Burton RS. 2015. Hybrid dysfunction and physiological

616 compensation in gene expression. Molecular Biology and Evolution 32:613-622.

617 Bindea G, Mlecnik B, Hackl H, Charoentong P, Tosolini M, Kirilovsky A, Fridman WH,

618 Pages F, Trajanoski Z, Galon J. 2009. ClueGO: a Cytoscape plug-in to decipher functionally

619

620

621 grouped gene ontology and pathway annotation networks. Bioinformatics 25:1091-1093. Coolon JD, McManus CJ, Stevenson KR, Graveley BR, Wittkopp PJ. 2014. Tempo and mode of regulatory evolution in Drosophila. Genome Res 24:797-808.

Counts JT, Hester TM, Rouhana L. 2017. Genetic expansion of chaperonin-containing TCP-1 (CCT/TRiC) complex subunits yields testis-specific isoforms required for spermatogenesis in planarian flatworms. Mol Reprod Dev 84:1271-1284.

Cutter AD. 2012. The polymorphic prelude to Bateson-Dobzhansky-Muller incompatibilities. Trends in Ecology \& Evolution 27:209-218.

627 Denver DR, Morris K, Streelman JT, Kim SK, Lynch M, Thomas WK. 2005. The

628 transcriptional consequences of mutation and natural selection in Caenorhabditis elegans. Nat

629 Genet 37:544-548.

630 Dobin A, Davis CA, Schlesinger F, Drenkow J, Zaleski C, Jha S, Batut P, Chaisson M,

631 Gingeras TR. 2013. STAR: ultrafast universal RNA-seq aligner. Bioinformatics 29:15-21.

632

Dobzhansky T. 1936. Studies on Hybrid Sterility. II. Localization of Sterility Factors in Drosophila Pseudoobscura Hybrids. Genetics 21:113-135. Edger PP, Smith R, McKain MR, Cooley AM, Vallejo-Marin M, Yuan Y, Bewick AJ, Ji L, Platts AE, Bowman MJ, et al. 2017. Subgenome Dominance in an Interspecific Hybrid, Synthetic Allopolyploid, and a 140-Year-Old Naturally Established Neo-Allopolyploid Monkeyflower. Plant Cell 29:2150-2167.

Elgvin TO, Trier CN, Torresen OK, Hagen IJ, Lien S, Nederbragt AJ, Ravinet M, Jensen H, Saetre GP. 2017. The genomic mosaicism of hybrid speciation. Sci Adv 3:e1602996. Gilad Y, Oshlack A, Rifkin SA. 2006. Natural selection on gene expression. Trends in Genetics 22:456-461.

Goncalves A, Leigh-Brown S, Thybert D, Stefflova K, Turro E, Flicek P, Brazma A, Odom DT, Marioni JC. 2012. Extensive compensatory cis-trans regulation in the evolution of mouse gene expression. Genome Res 22:2376-2384.

Haerty W, Singh RS. 2006. Gene regulation divergence is a major contributor to the evolution of Dobzhansky-Muller incompatibilities between species of Drosophila. Molecular Biology and Evolution 23:1707-1714.

648 Hermansen JS, Haas F, Trier CN, Bailey RI, Nederbragt AJ, Marzal A, Saetre GP. 2014. Hybrid speciation through sorting of parental incompatibilities in Italian sparrows. Mol Ecol 23:5831-5842.

Hermansen JS, Saether SA, Elgvin TO, Borge T, Hjelle E, Saetre GP. 2011. Hybrid speciation in sparrows I: phenotypic intermediacy, genetic admixture and barriers to gene flow. Molecular Ecology 20:3812-3822.

Hill G. 2017. The mitonuclear compatibility species concept. The auk 134:393-409.

Hodgins-Davis A, Rice DP, Townsend JP. 2015. Gene Expression Evolves under a House-ofCards Model of Stabilizing Selection. Molecular Biology and Evolution 32:2130-2140. 

functional annotation of uncharacterized proteins in an error-prone environment. Bioinformatics 31:1544-1552.

660 Kryvokhyzha D, Salcedo A, Eriksson MC, Duan T, Tawari N, Chen J, Guerrina M, Kreiner JM, Kent TV, Lagercrantz U, et al. 2019. Parental legacy, demography, and admixture influenced the evolution of the two subgenomes of the tetraploid Capsella bursa-pastoris (Brassicaceae). Plos Genetics 15:e1007949.

Landry CR, Wittkopp PJ, Taubes CH, Ranz JM, Clark AG, Hartl DL. 2005. Compensatory cis-trans evolution and the dysregulation of gene expression in interspecific hybrids of Drosophila. Genetics 171:1813-1822. Love MI, Huber W, Anders S. 2014. Moderated estimation of fold change and dispersion for RNA-seq data with DESeq2. Genome Biology 15.

669 Mallet J. 2007. Hybrid speciation. Nature 446:279-283.

Mallet J. 2005. Hybridization as an invasion of the genome. Trends in Ecology \& Evolution 20:229-237.

Malone JH, Michalak P. 2008. Gene expression analysis of the ovary of hybrid females of Xenopus laevis and X. muelleri. Bmc Evolutionary Biology 8:82.

Marques DA, Meier JI, Seehausen O. 2019. A Combinatorial View on Speciation and Adaptive Radiation. Trends in Ecology \& Evolution 34:531-544. Mayba O, Gilbert HN, Liu J, Haverty PM, Jhunjhunwala S, Jiang Z, Watanabe C, Zhang Z. 2014. MBASED: allele-specific expression detection in cancer tissues and cell lines. Genome Biol 15:405.

679 McGirr JA, Martin CH. 2019. Hybrid gene misregulation in multiple developing tissues within a recent adaptive radiation of Cyprinodon pupfishes. Plos One 14:e0218899. McManus CJ, Coolon JD, Duff MO, Eipper-Mains J, Graveley BR, Wittkopp PJ. 2010. Regulatory divergence in Drosophila revealed by mRNA-seq. Genome Res 20:816-825. Mugal CF, Wang M, Backstrom N, Wheatcroft D, Alund M, Semon M, McFarlane SE, Dutoit L, Qvarnstrom A, Ellegren H. 2020. Tissue-specific patterns of regulatory changes underlying gene expression differences among Ficedula flycatchers and their naturally occurring F1 hybrids. Genome Res 30:1727-1739.

Muller HJ. 1942. Isolating mechanisms, evolution, and temperature. Biol Symp. 6:71-125. Paronetto MP, Sette C. 2010. Role of RNA-binding proteins in mammalian spermatogenesis. Int J Androl 33:2-12.

690 Phillips BT, Williams JG, Atchley DT, Xu X, Li JL, Adams AL, Johnson KL, Hall TMT. 2019. Mass spectrometric identification of candidate RNA-binding proteins associated with Transition Nuclear Protein mRNA in the mouse testis. Sci Rep 9:13618. Ranz JM, Namgyal K, Gibson G, Hartl DL. 2004. Anomalies in the expression profile of interspecific hybrids of Drosophila melanogaster and Drosophila simulans. Genome Res 14:373-379.

Ravinet M, Elgvin TO, Trier C, Aliabadian M, Gavrilov A, Saetre GP. 2018. Signatures of human-commensalism in the house sparrow genome. Proc Biol Sci 285.

\section{Renaut S, Nolte AW, Bernatchez L. 2009. Gene expression divergence and hybrid} misexpression between lake whitefish species pairs (Coregonus spp. Salmonidae). Molecular Biology and Evolution 26:925-936.

Rest JS, Morales CM, Waldron JB, Opulente DA, Fisher J, Moon S, Bullaughey K, Carey LB, Dedousis D. 2013. Nonlinear fitness consequences of variation in expression level of a eukaryotic gene. Molecular Biology and Evolution 30:448-456.

Rieseberg LH, Archer MA, Wayne RK. 1999. Transgressive segregation, adaptation and speciation. Heredity (Edinb) 83 ( Pt 4):363-372. 
Rieseberg LH, Raymond O, Rosenthal DM, Lai Z, Livingstone K, Nakazato T, Durphy JL, sunflowers facilitated by hybridization. Science 301:1211-1216.

711 Rowe M, Whittington E, Borziak K, Ravinet M, Eroukhmanoff F, Saetre GP, Dorus S. 2020.

712 Molecular Diversification of the Seminal Fluid Proteome in a Recently Diverged Passerine

713 Species Pair. Molecular Biology and Evolution 37:488-506.

714 Runemark A, Eroukhmanoff F, Nava-Bolanos A, Hermansen JS, Meier JI. 2018.

715 Hybridization, sex-specific genomic architecture and local adaptation. Philos Trans R Soc

716 Lond B Biol Sci 373.

717 Runemark A, Trier CN, Eroukhmanoff F, Hermansen JS, Matschiner M, Ravinet M, Elgvin

718 TO, Saetre GP. 2018. Variation and constraints in hybrid genome formation. Nat Ecol Evol

719 2:549-556.

720 Runemark A, Vallejo-Marin M, Meier JI. 2019. Eukaryote hybrid genomes. Plos Genetics

721 15:e1008404.

722 Ryan MT, Hoogenraad NJ. 2007. Mitochondrial-nuclear communications. Annu Rev

723 Biochem 76:701-722.

724 Shannon P, Markiel A, Ozier O, Baliga NS, Wang JT, Ramage D, Amin N, Schwikowski B, 725 Ideker T. 2003. Cytoscape: a software environment for integrated models of biomolecular

726 interaction networks. Genome Res 13:2498-2504.

727 Summers-Smith JD. The Sparrows: A Study of the Genus Passer: T \& AD Poyser.

728 Svensson L, Grant PJ, Mullarney K, Zetterstroem D. 1999. Gyldendals store fugleguide:

729 Europas og middelhavsområdets fugler i felt: Gyldendal.

730 Szklarczyk D, Gable AL, Lyon D, Junge A, Wyder S, Huerta-Cepas J, Simonovic M, networks with increased coverage, supporting functional discovery in genome-wide experimental datasets. Nucleic Acids Res 47:D607-D613.

734 Taylor SA, Larson EL. 2019. Insights from genomes into the evolutionary importance and prevalence of hybridization in nature. Nat Ecol Evol 3:170-177.

Trier CN, Hermansen JS, Saetre GP, Bailey RI. 2014. Evidence for mito-nuclear and sexlinked reproductive barriers between the hybrid Italian sparrow and its parent species. Plos Genetics 10:e1004075.

Wagner DN, Curry RL, Chen N, Lovette IJ, Taylor SA. 2020. Genomic regions underlying metabolic and neuronal signaling pathways are temporally consistent in a moving avian hybrid zone. Evolution 74:1498-1513.

Wang L, Wang S, Li W. 2012. RSeQC: quality control of RNA-seq experiments. Bioinformatics 28:2184-2185.

Wittkopp PJ, Haerum BK, Clark AG. 2004. Evolutionary changes in cis and trans gene regulation. Nature 430:85-88.

Yu G, Wang LG, Han Y, He QY. 2012. clusterProfiler: an R package for comparing

748 
A

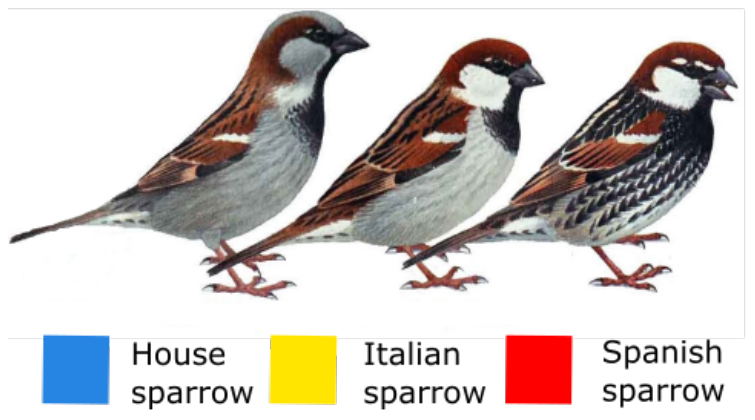

749

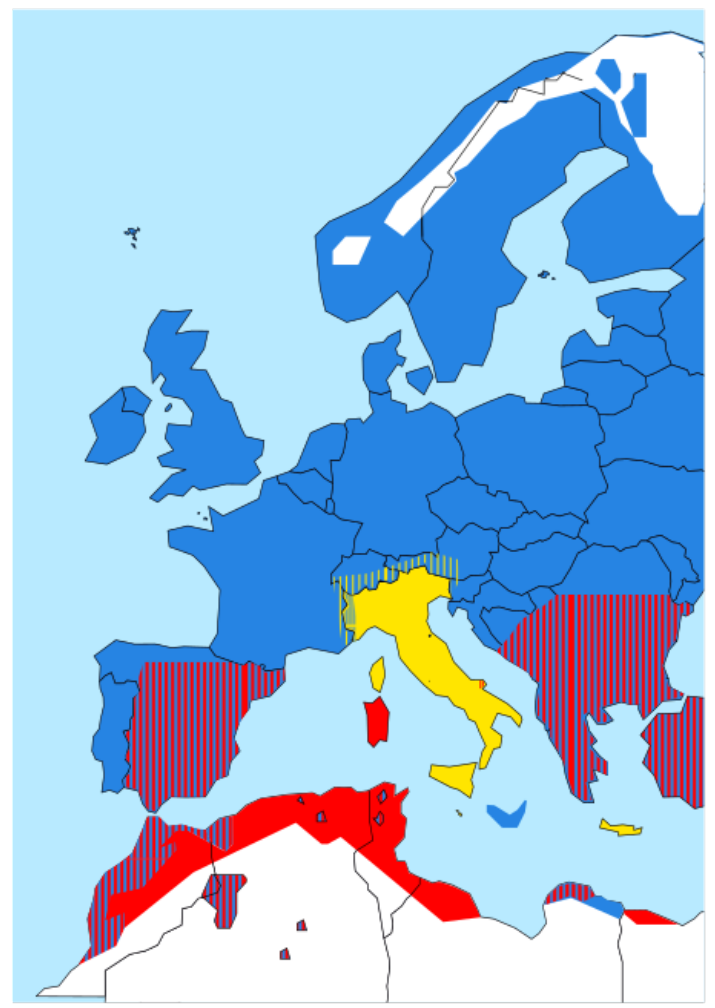

B

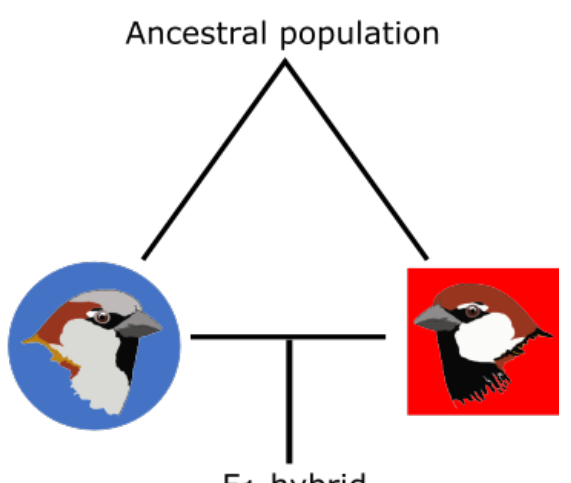

$F_{1}$ hybrid

$\mid$

Time 


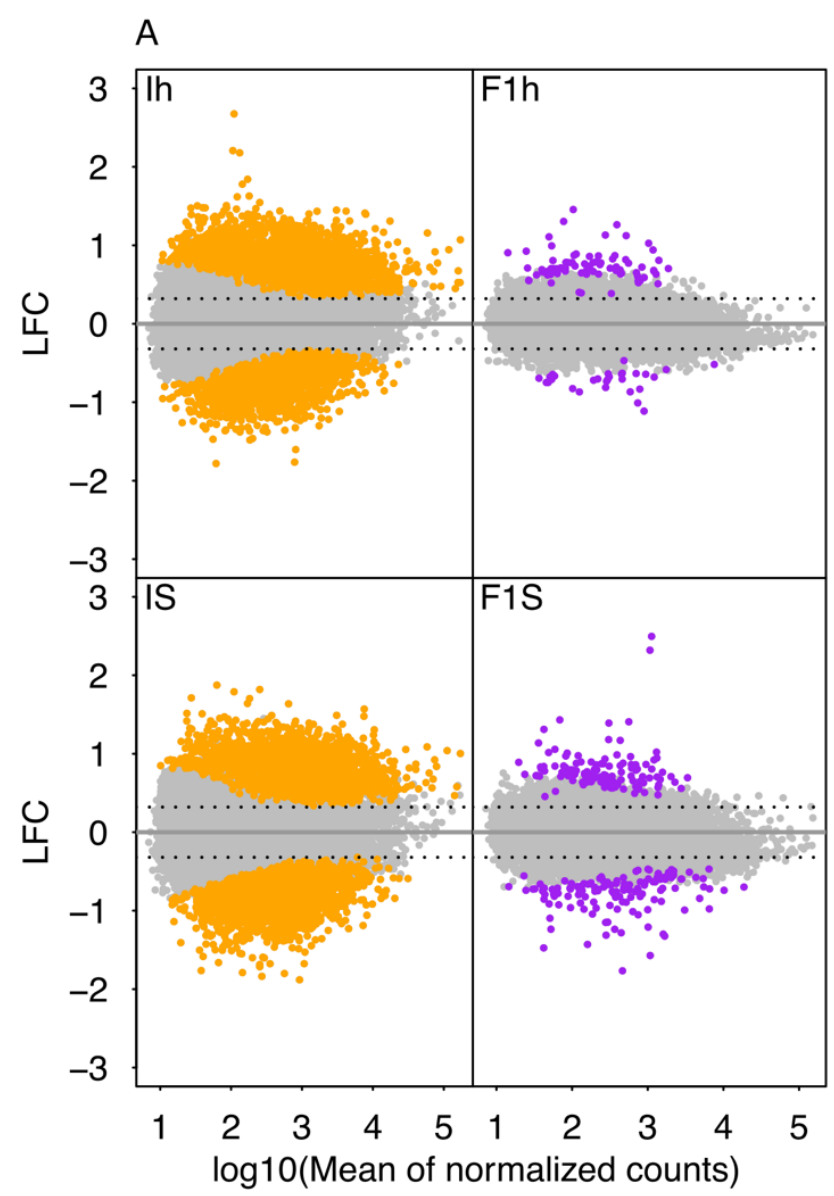

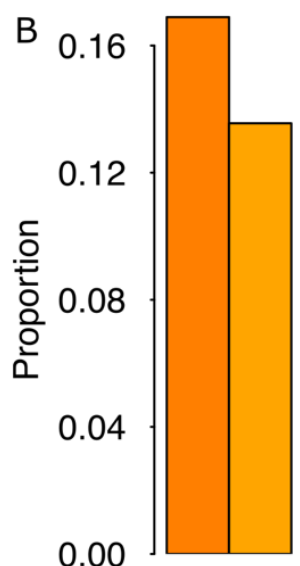

Ih

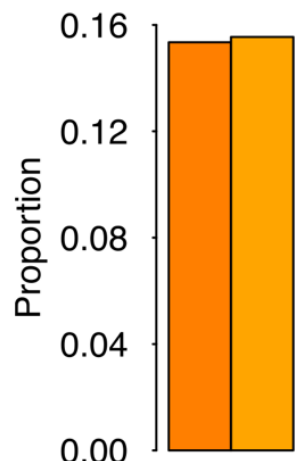

IS
C

Ih

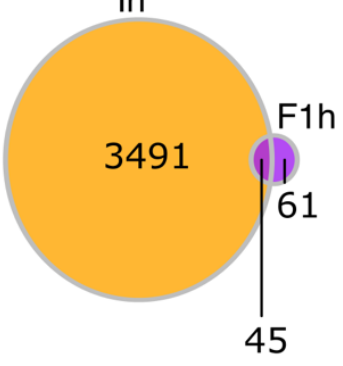

IS

F1S

F1h

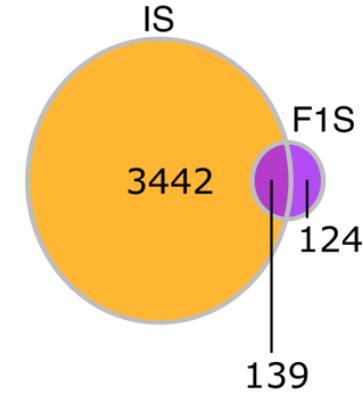

754

755

756

757

758

759

760

761

762

763

764

765

766 
A

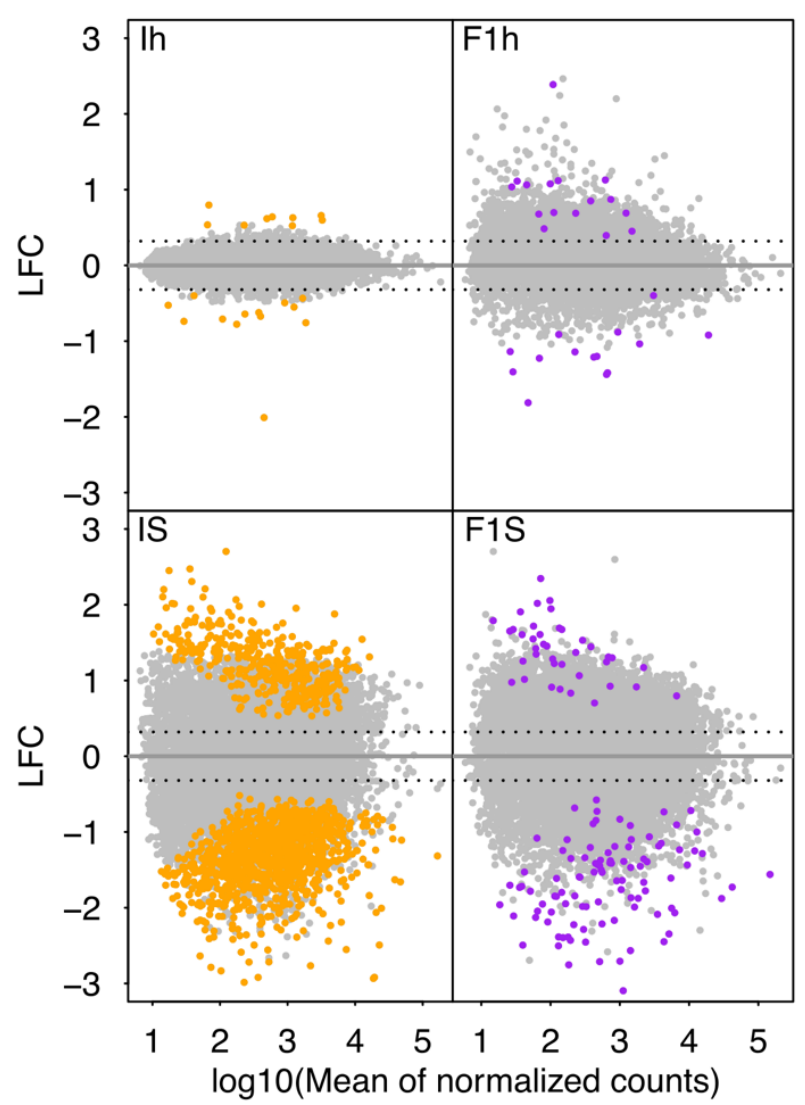

B

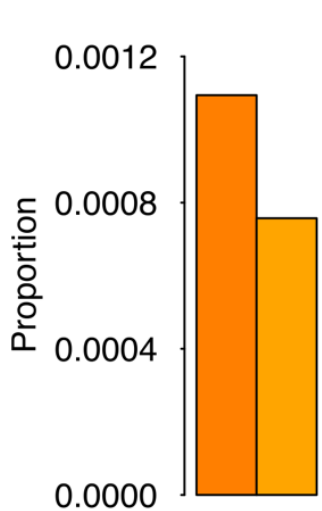

Ih

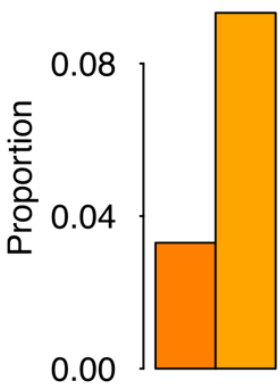

IS
C
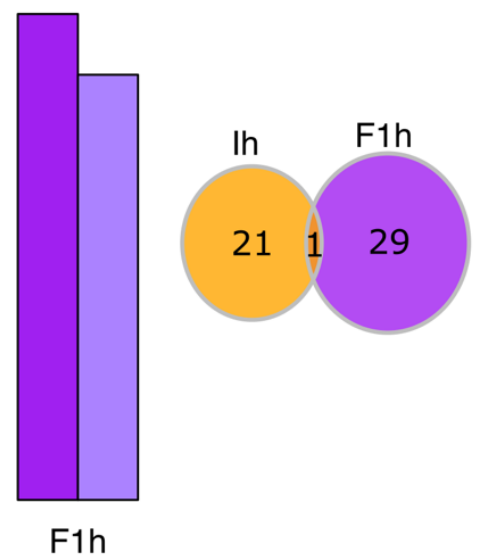

IS

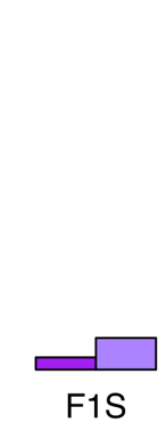

767

768

769

770

771

772

773

774

775

776

777

778

779 
A

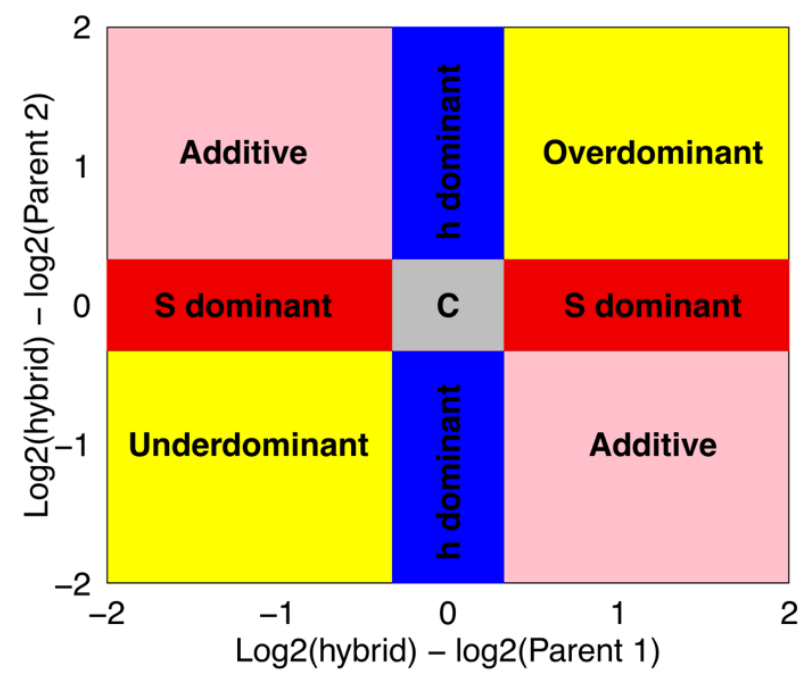

C

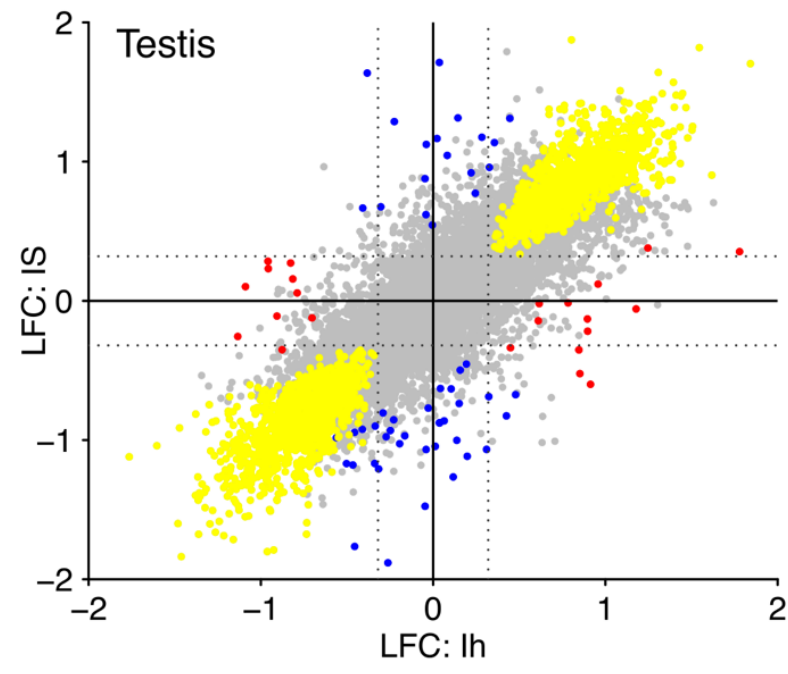

E

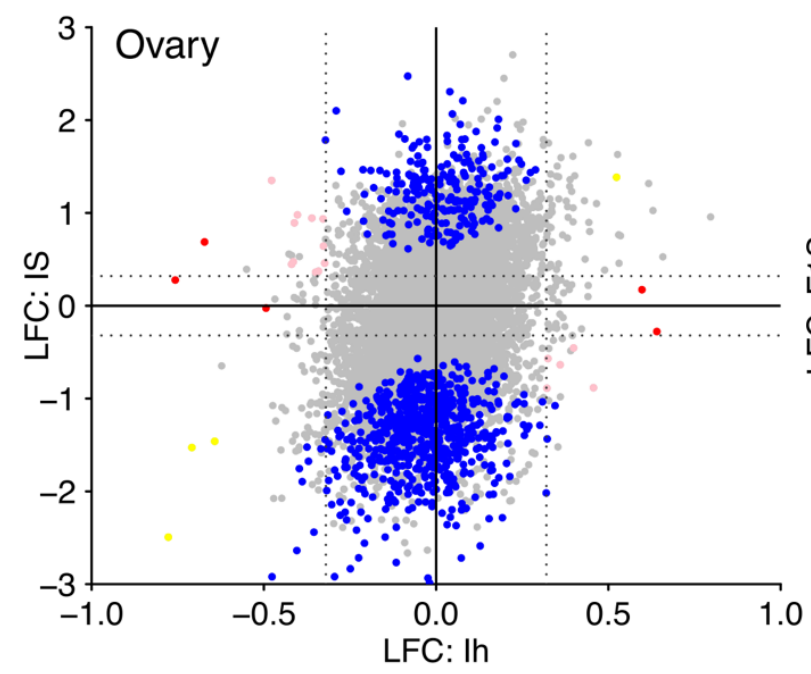

B

Dhouse $\square$ hybrid $\square$ Spain
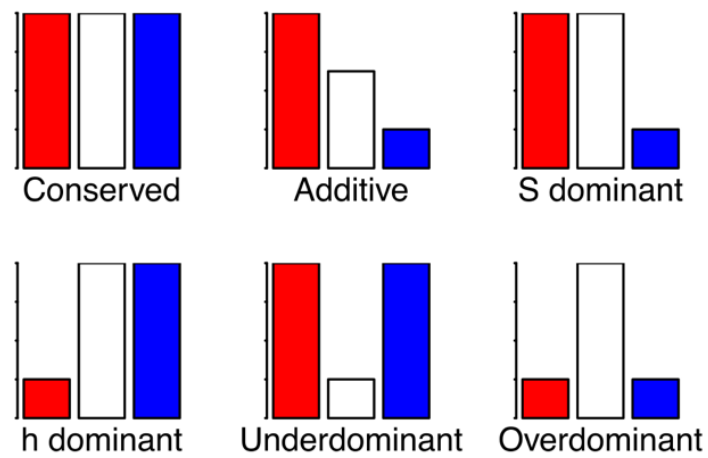

D

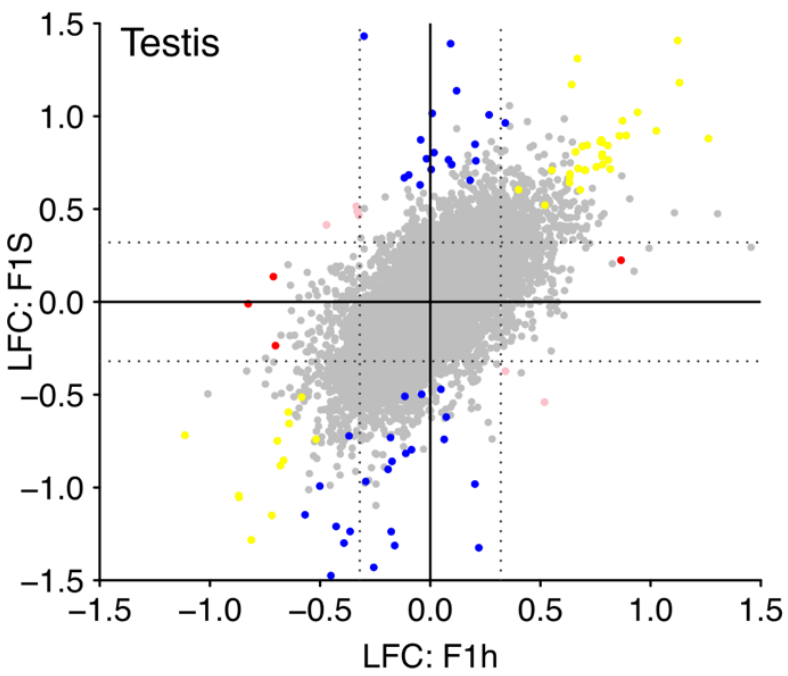

F

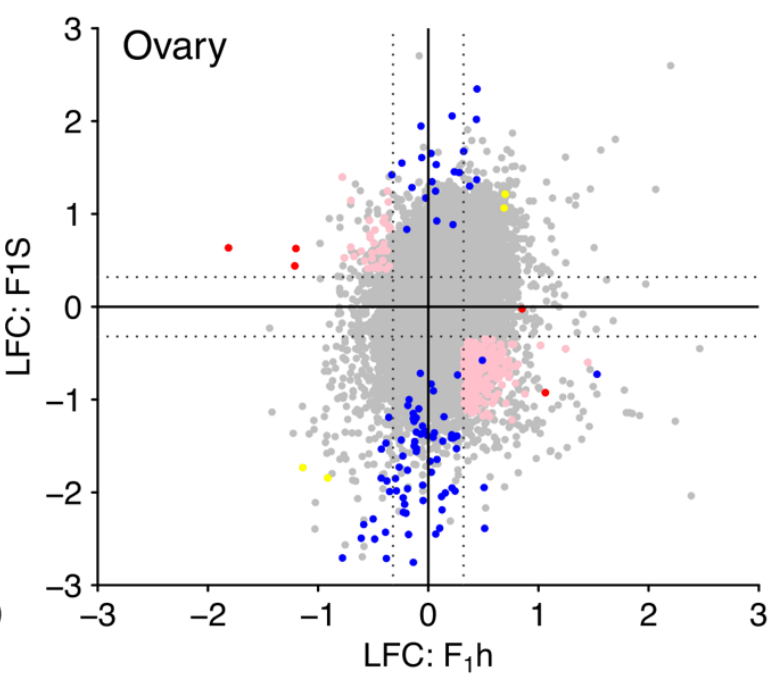


bioRxiv preprint doi: https://doi.org/10.1101/2021.04.15.440043; this version posted April 21, 2021. The copyright holder for this preprint (which was not certified by peer review) is the author/funder. All rights reserved. No reuse allowed without permission.

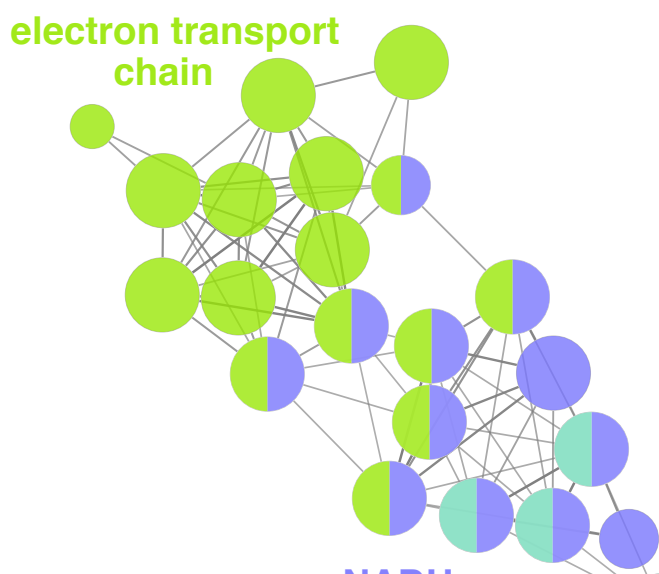

NADH

dehydrogenase complex assembly

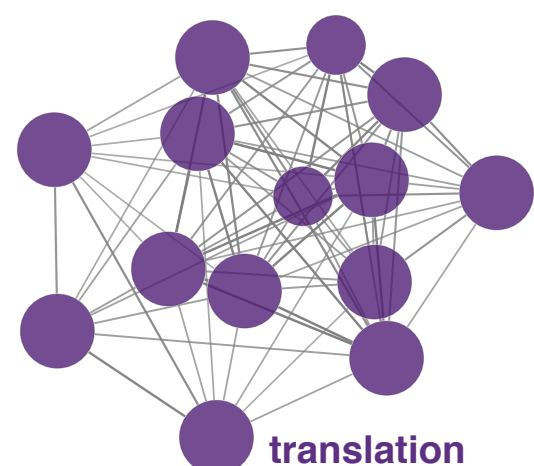

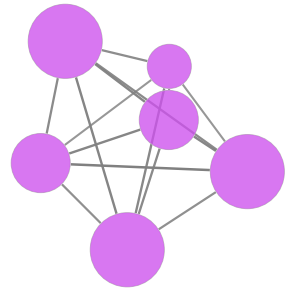

translation regulator activity

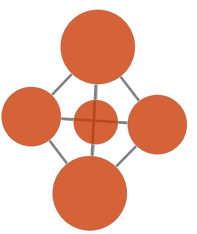

SRP-dependent cotranslational
protein targeting pyruvate to membrane

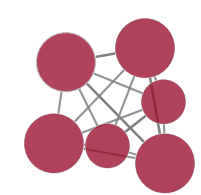

binding of sperm to zona pellucida

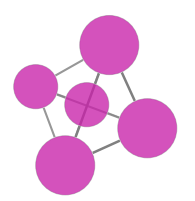

modification by host of symbiont morphology or physiology 